\title{
On the Effectiveness of Gamified Risk Management Workshops: Evidence from German SMEs
}

\author{
Avo Schönbohm, Alexandra Jülich \\ Berlin School of Economics and Law \\ avo.schoenbohm@hwr-berlin.de \\ s_juelich@stud.hwr-berlin.de
}

\begin{abstract}
This study analyzes the potential benefits gamification can offer to SMEs in the area of risk management. A structured review of the topic of risk management in SMEs and previous studies of the application of gamification to risk management forms a theoretical framework. A gamified risk management workshop is devised which is used as a treatment for three German SMEs. This article contains a description of the developed workshop, the applied methodology and the respective results. While following a quasi-experimental action research approach, it becomes evident that the gamified workshop has the potential to motivate the participants, increase their knowledge on risk management and foster cognitive and group de-biasing. The findings suggest that gamification can be a valuable tool for SMEs to enhance their risk management process.
\end{abstract}

Keywords: Gamification, Gamified Workshop Design, Risk Management, SMEs

\section{Introduction}

Can gamification improve the effectiveness and efficiency of risk management in SMEs? Multiple researchers suggest that the main reasons for SMEs risk management failure are lack of motivation, lack of knowledge and the susceptibility to cognitive biases [1, 2, 3]. Considering the overlap between the weaknesses identified in the risk management process in SMEs and the perceived benefits of gamification, it seems astounding that this topic has remained underresearched until today [4]. There are professional serious games on risk management and articles about the potential use of gamification in risk management, but only Bajdor's and Dragolea's exploratory paper on gamification in risk management has so far academically treated the topic [5], [6].

In order to answer the question whether gamification enhances the effectiveness and efficiency of risk management in SMEs, a number of sub-questions are addressed.

1. Can selected game mechanics be used to solve the issue of lacking motivation in risk management?

2. Can selected game mechanics be implemented in order to provide SMEs with a clearly structured risk management process, allowing for revelation of tacit knowledge and its free exchange?

3. Can selected game mechanics facilitate a setting in which cognitive biases are reduced?

As gamification has the potential to improve processes in multiple ways, it is important to determine if it can and should be used for very specific purposes like increasing motivation or revealing tacit knowledge only, or if it can be employed in a broader scope with the idea of general improvement in mind.

The method applied is quasi-experimental action research at three German SMEs with a gamified risk identification and evaluation workshop as a proposed treatment. Quantitative and qualitative post-treatment data was analyzed, which allowed for a triangulation of the research results. The workshop design was enhanced after each experiment taking into account the respective findings. The workshop was first tested with students and then applied at three SMEs with four to six participants per workshop. The analysis of the data suggests a positive influence of the applied game mechanics on the motivation of the participants 


\section{Theoretical Foundations}

\subsection{The psychology of risk management}

Risk management deals with the identification and reflective handling of uncertain events with negative consequences for the respective organization. The ISO guide 73 defines risk as the "effect of uncertainty on objectives". Therefore, risk management should play a crucial role in any company's strategic management, as it defines the risk appetite, the respective actions and provides reasonable assurance that the company can reach its previously defined goals [7]. Understanding risk management as a key element for company success underlines the importance of implementing an efficient risk management process - even or especially in SMEs. Risk identification is considered by many authors to be the most important element of the entire risk management process [8]. Falkner and Hiebl conclude that significant emphasis should be placed on identifying a variety of typical risks in SMEs as a prerequisite for their later management [1]. Additionally, Abotsi et al suggest that the ability of SME managers to address the challenges of a competitive global market is largely influenced by their ability to carefully identify and analyze the types of risks their business faces [3]. The focus of this study lies on providing SMEs with an efficient risk identification and assessment process.

Multiple reasons exist why SME are hesitant to engage in risk management [9]. Three interrelated factors can be identified when analyzing why SMEs are often unsuccessful in implementing an effective risk management system: Lack of motivation, lack of knowledge and the susceptibility to cognitive biases. Many SMEs do not - or not adequately - apply risk management practices because they realize the scarcity of their resources and often figure they cannot afford to rededicate them [8]. Therefore, they choose to focus on revenue driving activities [10]. Although risk management might function as a value driver in the long run, this is often neglected, because the value created by risk management is perceived as difficult to quantify [11]. These factors all adversely affect a company's and its employees' motivation to engage in risk management as a whole.

Another aspect that hinders companies from successfully engaging in risk management is a lack of knowledge. The knowledge about risk management is mostly informal in SMEs, complicating the effective build-up of risk management skills among employees [12]. Employees in SMEs rely on tacit knowledge, as opposed to formally defined process knowledge. Most SMEs seem to be aware of the risk that losing employees' tacit knowledge poses. However, they are still reluctant to invest in employee training [1]. This lack of knowledge further diminishes the motivation to invest in risk management, making limited financial and human resources in SMEs the main reason for their partial inability to effectively manage their risks $[13,14,15,16]$.

Table 1. Important cognitive biases.

\begin{tabular}{l|l|l}
\hline Cognitive Bias & Definition & Source \\
\hline Groupthink & $\begin{array}{l}\text { The tendency of group members to suppress any dissent to remain at a } \\
\text { (perceived) state of unanimity within the group, reducing innovation } \\
\text { and creativity. }\end{array}$ & {$[21,22]$} \\
\hline Authority Bias & $\begin{array}{l}\text { The tendency to obey authorities even when they should be challenged } \\
\text { and/or the resulting actions have negative effects on oneself or others. }\end{array}$ & {$[2]$} \\
\hline Conformity Bias & $\begin{array}{l}\text { The tendency to take behavioral cues from peers, with the need for } \\
\text { social approval overriding common sense. }\end{array}$ & {$[23,24]$} \\
\hline Availability Bias & $\begin{array}{l}\text { The tendency of assessing the probability of an event by the data most } \\
\text { conveniently available. } \\
\text { The tendency to have inflated confidence in one's own judgments and } \\
\text { ability to impact future events. } \\
\text { The tendency to make estimates based on an initial anchored number } \\
\text { or information. }\end{array}$ & {$[25][26][28]$} \\
\hline Overconfidence & [25] \\
\hline Anchoring &
\end{tabular}

Considering that risk is a derivative of uncertainty, risk management is always prone to human error. The brain relies on experience, rules of thumb and a personal context - generally on what are called heuristics. These are typically used when facing complex and or incomplete information in order to simplify complex decisions [17, 18], which can eventually lead to cognitive biases [17]. Cognitive biases are errors in judgment based on the misconceptions of facts, memory errors, probability errors and or social influence and are the basis of irrational reasoning [19]. The human 
brain performs an accuracy-effort trade-off sacrificing the accuracy of a decision in favor of speed [20]. Minimizing the cognitive biases that can foster not only poor decision making but also ethical and legal wrongdoing is crucial to risk management [2].

Table 1 provides an overview of some of the most known and influential cognitive biases.

\subsection{The psychology of gamification and gamified activities}

Gamification can be understood as the transfer of game mechanics and game elements to non-game contexts with the objective to elicit a specific behavior. Most definitions define games as characterized by rules and competition or strife towards specified, discrete outcomes or goals by human participants [29]. Using game elements means that classic game design ideas are leveraged to create a gameful experience. Scientific research in fields like psychology, sociology and computer science agrees upon the idea of play - structured in predefined frameworks such as games or game like environments - as a promising solution for fostering motivation [30]. Many areas of business could benefit from gamification as it can help to change behavior, to develop skills; and to enable innovation [31].

Therefore, a gamified risk management workshop as a treatment for SMEs was developed. It contains multiple game elements but does not solely aim at creating a playful experience, but also at transferring knowledge and eliciting desired behavior. Multiple researchers have identified positive effects of gamification on motivation, learning and (corporate) culture [32,33].

To achieve a long term behavioral change, gamification has to be applied in a way that the people involved in the process are intrinsically motivated to engage in it. Reasons for engaging in an activity or behavior are explained by the Self-Determination Theory by Deci and Ryan, who claim that intrinsic motivation is essentially based on the fulfillment of three psychological needs [34], namely:

- Competence: the need to feel mastery and to perform so well as to make a difference.

- Autonomy: the possibility to make decisions in a given regulatory framework.

- Relatedness: the development of a relationship to the people and subject.

Ongoing game enjoyment and immersion can be understood as experiential signatures of need satisfaction: What is described as "fun" by the players is the actual experience of need satisfaction [35]. Zichermann and Cunningham also list mastery, distress, having fun, and socializing as individual motivators for people to play games [36]. This leaves room to assume that if gamification is aiming at a longtime change in behavior, it should consider the prospective players of a gamified application or process in order to allow them to fulfill these needs [37]. Bartle determined four main different player types according to their behavior, further stressing the importance of knowing player personalities [38].

Gamification is considered to be suitable for many tasks, especially for those with specific rules or a certain degree of standardization, which is often the case in an elaborate risk management system. Lichtenvoort recognizes the potential of applying gamification to risk management and suggests awarding gamepoints for identified risks and assigns the iterations of identifiying contingent risks to a level structure [39]. Thus, it comes as no surprise that risk management has been the topic of professional serious games [40]. Bajdor and Dragolea come to the conclusion that game elements might greatly contribute to increasing the involvement of employees and therefore increase the effectiveness of risk management [6]. Their study, however, remains methodologically limited. This study was conducted as an exploratory approach of conceptualizing the possibilities and opportunities for the application of gamification to risk management.

\section{Research Philosophy}

\subsection{Conceptual Model}

The following figure shows the identified problems and the derived hypotheses. It visualizes how game mechanics can be used to fulfill the necessary requirements of both the environment and the employee-behavior in an effective risk management process. It is assumed that game mechanics like points, time limits or a failure safe environment can, create the desire to perform in a competitive way, that encourages desired behavior and that addresses the issue of cognitive biases. With this, a new work-environment is created in which employees can satisfy their needs for mastery, autonomy and relatedness more easily. All competitive game elements support the feeling of mastery. Game elements like a failure safe environment increase a person's feeling of autonomy 
and the discussions used to address cognitive biases will foster their relatedness with the issue at hand. Eventually, through this, motivation, the revelation of tacit knowledge and the mitigation of cognitive biases might be ignited.

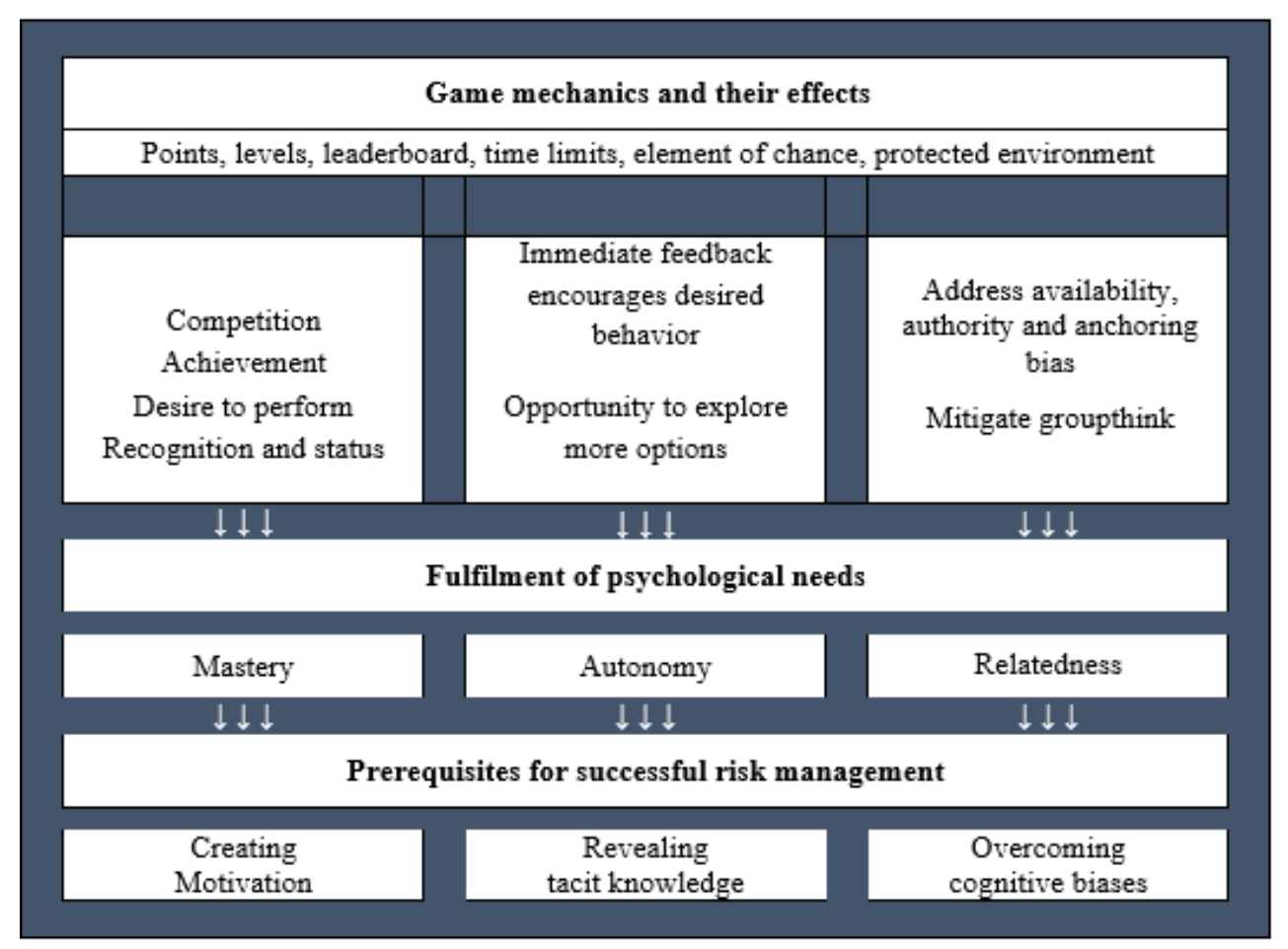

Figure 1. Conceptual model of gamification in risk management.

\subsection{Hypotheses development}

To answer the research question, five hypotheses were developed and tested with the data collected during the workshop as well as after the treatment.

The following hypotheses were tested:

H1: Game elements such as points, leaderboards, and time limits are motivating in risk management at SMEs as they drive competition and provide the participants with a feeling of mastery.

H2: Receiving feedback both from the game mechanics and from colleagues as well as the opportunity to give feedback motivates participants in gamified risk management workshops, because it increases a feeling of relatedness and autonomy.

H3: Game elements can help to build a risk management process that minimizes the influence of cognitive biases and to improve decision making in general.

H4: The use of gamification can help creating a clear and structured risk management process that is easy to follow, to visualize and to replicate.

H5: A gamified risk management workshop has the possibility to convey knowledge and teach the practical application of theory in a safe environment.

\subsection{Research methods}

The term action research was coined by the social psychologist Kurt Lewin, who referred to it as problem-centered research, recognizing that social systems can only be studied by changing them [41, 42, 43, 44]. It entails the collaboration between researchers and practitioners to fulfill the aim of overcoming an identified (social) problem and to bring about change and bridge the gap between theory and practice [41, 45]. In this study, this collaboration occurred in form of a gamified workshop. This workshop functioning as a treatment is further improved based on the received feedback, generating the spiraling process of continuous improvement until enough data is collected [46]. This is an important characteristic of action research [44, 47]. Accordingly, Avison et al conclude that the researcher should test a theory with practitioners in real situations, 
gain feedback from this experience, modify the theory as a result of this feedback and test it again [48]. The action research approach was conducted in a quasi-experimental way, allowing to make assumptions about the treatment in a timely fashion. The workshops were improved after each cycle, but tested with each company only once instead of multiple times. Additionally, quasiexperimental research allows for the use of qualitative data analysis, which is a key concept of action research [49].

Action research is an autonomous methodology in the critical social sciences and therefore offers an adequate alternative to other empirical-analytical methodologies [43]. McTaggart suggests that the validity of the results can be supported by a triangulation of observations and interpretations [50]. This additional combination of both quantitative and qualitative methods is also suggested by the concept of quasi-experimental research design and is therefore applied to overcome the challenges of scientific data collection and evaluation [51].

The questions included in the survey aimed at determining the respondents' opinion on the workshop. To maintain the anonymity of the participants, personal characteristics were not asked in this survey. The survey contained 15 questions using a Likert scale, offering the respondents the answers: strongly agree, agree, neutral, disagree and strongly disagree.

For data analysis purposes, the questions were coded with a system established before the data entry process as suggested by Saunders [52]. The quantitative data received from the survey is presented using descriptive statistics, allowing proper visualization and analysis.

After the workshop and the completion of the survey, focus group interviews were conducted. A focus group, or 'focus group interview', is a group interview that encompasses the need for interactive discussion amongst participants [53]. As suggested by Saunders, the focus groups consisted of four to eight workshop participants, thereby also fulfilling the selection criteria of having certain topic related characteristics in common as mentioned by Krueger and Casey [52, 54]. Their research also suggests that after three or four focus groups, information saturation is usually reached and no new insights are generated. A voice recorder was used during the interview to allow for later transcription, which followed basic transcription rules suggested by Dresing [55]. The data from the focus groups was first summarized, rephrasing long sentences in a few words [56]. Afterwards, the data was categorized in order to increase its comparability using the software program Maxqda.

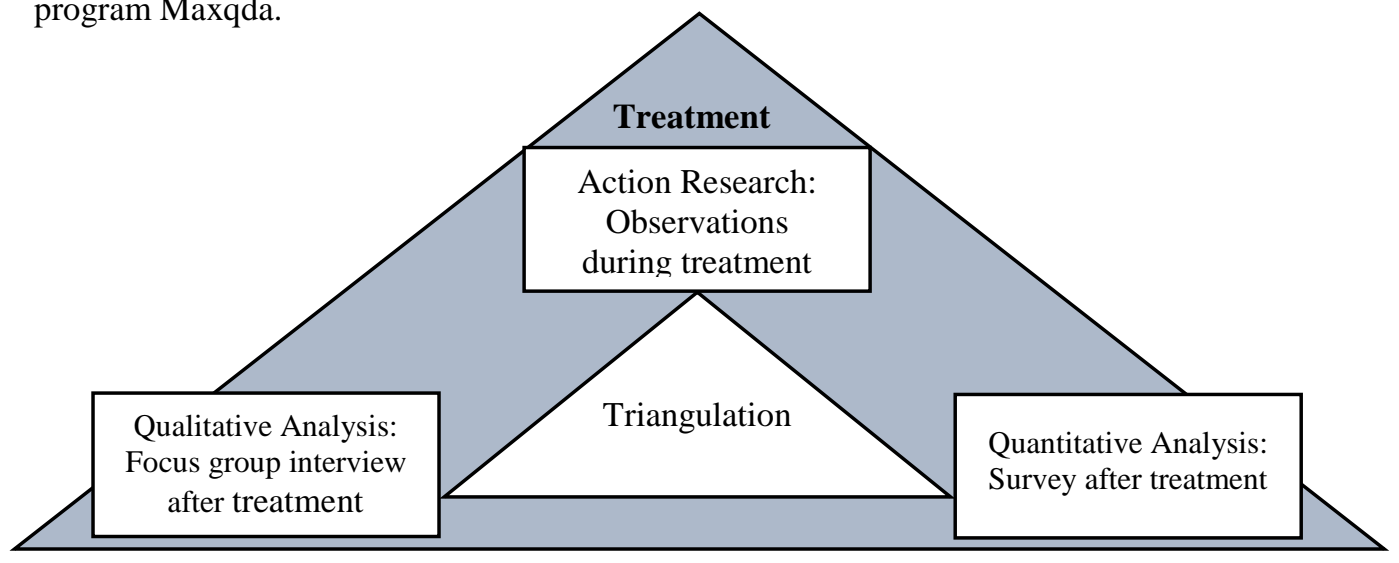

Figure 2: Research methodology

The concept of triangulation was applied in order to support the result observations of the quasiexperimental action research conducted in this study. The triangulation included a reflection on the observation of the participants during the treatment based on the data from the qualitative and quantitative analysis to mitigate classic observer bias. The analysis of both quantitative and qualitative data allows for a deeper understanding of the participants' opinions.

\subsection{Experiment design: gamified risk management workshop}

To assess possible effects of the gamification of the risk management process in SMEs, a gamified risk management workshop emulating a treatment for the identified problems was developed. This was consequently tested in slightly enhanced variations with three companies in Germany. The idea of this workshop is to create a structured risk management process. Simultaneously, the process was devised to be more engaging, informative and measurable by using game elements. The workshop was structured by dividing groups of tasks into levels, during which participants could earn points, which were later displayed in a leaderboard between levels. Each workshop 
lasted between 1.5 and 2 hours with a subsequent 20 minutes focus group interviews. Throughout the whole workshop, the researcher served as a moderator, explaining the rules of each level, supporting the participants and enforcing the time limits. However, the researcher did not interfere with the participants' discussions or results, but rather observed them. Additionally, the researcher entered the point count into a previously prepared excel spreadsheet in order to calculate the leaderboard.

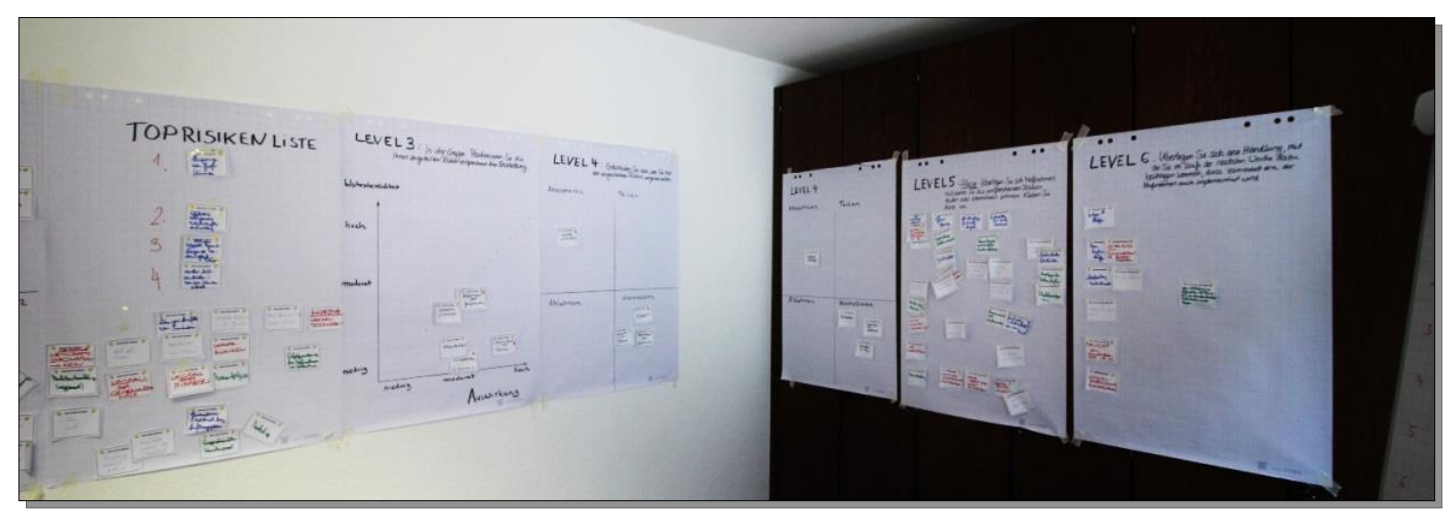

Figure 3: The workshop.

In the first level, the participants were asked to fill out the areas Strength, Weaknesses and Opportunities in a SWOT analysis for their own company with the use of idea cards. For each idea card they posted to the chart, they were awarded 5 points. In the second level, they were asked to do the same - only focusing on possible threats. Then the participants had the possibility to award "stars" to the risks they thought are most important. With every star the idea card owner earned 5 more points, thus rewarding the quality of an idea. With this evaluation system, a list of the top risks was developed, which would be treated in the further levels.

In level 3, the participants were randomly divided into two teams and asked to position the top risks on a prepared risk map. The teams were given ten minutes to unanimously decide on where to position the risks on the risk map. The random assignment of teams was used in order to match people of different backgrounds and expertise together to foster more varied discussions. The aim was to address the availability bias and possibly hierarchical issues. Afterwards, the teams had to explain why they had positioned a specific risk in the way they did. The other team could then either agree with the explanation, awarding the explaining team's players ten points each, or disagree. The latter caused a new discussion, in which the two teams had to determine a position for the risk that everyone agreed with. Including the point system into the discussions prevented the two teams from simply agreeing with each other, reducing negative influences like groupthink and the conformity bias. In level 4 , the two groups had to sort the risks into the four quadrants: accept, reject, control, share. Again, a discussion explaining the respective assessments took place like in level 3. In level 5, the participants were asked to privately brainstorm measures against the risks they had identified and evaluated, earning points for filling out their idea cards. The ideas were again evaluated with the use of star stickers, leading to the development of a top measure list. Level 6 was used to wrap up the workshop with the participants formulating one concrete task for themselves to make sure the top measures would get implemented.

Levels 1,2 and 5 aimed at motivating the competitive and the exploratory player type. Being able to gain points, appearing on a leaderboard and receiving recognition of others through awarded stars should encourage the competitive player to do his or her best. The exploratory type is assumed to enjoy the ability to voice all of his or her ideas and to see what others think about them. Having the participants write down their ideas anonymously and silently allowed participants of all ranks to contribute because existing hierarchical structures were alleviated. Similarly, the stars were solely allocated based on content rather than likeability or hierarchical pressure. With this, both the authority and the conformity bias were addressed. Levels 3 and 4 were especially designed to engage the social player type by allowing them to work in a team, possibly even with people outside of their regular circle. All levels had a time limit, which was used to drive competition and to ensure the maximum duration of two hours of the workshop.

The different game mechanics applied in the workshop were selected in order to appeal to many different player types. As the workshops were scheduled to be held at consulting companies, it was expected that the competitive player type would be dominant. That is why the more social 
activities like the group discussion still included the game element of receiving points for the best line of argumentation. Testing the workshop with a social company was a welcome opportunity to receive feedback about the effectiveness of the workshop outside of the competitive consulting environment. The participants in the social enterprise indicated a preference for social game mechanics. The game mechanics were not distinctively chosen to fit certain gender expectations. However, with the application in the consulting field in mind, more competitive game mechanics were used which might imply a more masculine orientation.

Throughout the workshop, the participants learned how a structured and logical approach to risk management might look like, including typical tools like a risk map. The addition of multiple game elements to the process should increase the participants' motivation and simultaneously increase their performance.

Since risk management and gamification are both particular topics that need at least some level of interest from the company side, small consulting companies were contacted. One of them suggested working with one of their clients, a company working with the mentally and physically challenged, providing the opportunity to test the workshop in a different setting, in order to make broader assumptions about its efficiency. None of the participants had participated in a gamified risk management workshop so far. As experiences of the companies regarding other workshops differed, there was no direct comparison possible. In each case, the authors contacted the companies and asked them if they were willing to participate in the research project and if they could provide at least four participants. In company 1 and 3, all employees participated voluntarily and in company 2, the department heads participated voluntarily. The participants of company 3 were all middle-aged men (between 40 to 50), the participants of company 2 were also middleaged but equally distributed between men and women. In company 1 one middle aged men, two middle aged women and 3 younger men (presumably below 30) participated. However, it is important to realize that these assumptions about the participants' personal characteristics stem from the researchers' observation - they were not asked for directly in the survey.

Table 2. Population of the study.

\begin{tabular}{l|c|c|c}
\hline \# of Participants & $\begin{array}{c}\text { Company 1 } \\
\text { (Consulting) }\end{array}$ & $\begin{array}{c}\text { Company 2 } \\
\text { (Company for } \\
\text { mentally challenged) }\end{array}$ & $\begin{array}{c}\text { Company 3 } \\
\text { (Consulting) }\end{array}$ \\
\hline Workshop & 6 & 6 & 4 \\
\hline Survey & 6 & 6 & 4 \\
\hline Focus Group & 6 & 6 & 4 \\
\hline
\end{tabular}

\section{Discussion of results}

\subsection{Results of the hypotheses testing}

The previously defined hypotheses where tested by triangulating the data, generated from observing the workshop, the survey and the focus groups as described earlier.

H1: Game elements such as points, leaderboards, and time limits are motivating in risk management at SMEs as they drive competition and provide the participants with a feeling of mastery.

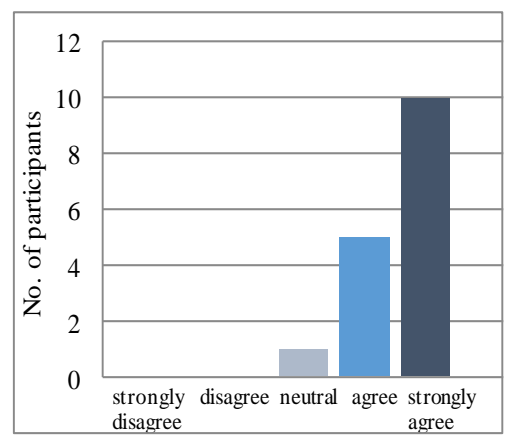

Figure 3. Question 1: The workshop was motivating. 
The results of the survey indicate the generally favorable perception of the gamified risk management workshop by almost all the participants. Only one participant felt neutral about the motivating effect of the workshop.

To determine how this motivation was achieved, the three game mechanics points, time limits and the leader board were examined. Both the survey and the focus group interviews, as well as the observation of the workshop, showed that there were differences among the participants' perceptions of the game mechanics. Even though 11 participants agreed or strongly agreed that the points were motivating, 3 thought that they were not motivating (see figure 5). The groups themselves were unanimous with their evaluations - company 1 and 3 reacted mainly positive to the points, whereas company 2 was rather critical.

"I really liked the points in order to put some pressure on the people, to get them to participate." 5:18-7:05 (C1_P1)

"Assigning points and the leaderboard weren't really important for me." 5:50 - 7:05 (C2_P2)

"I liked the points." 2:51-2:54 (C3_P3)

The time limits were perceived not necessarily as a game mechanic, driving competition and performance, but rather as a useful tool to keep the discussion time to a limit instead of allowing people to drift off into personal conversations.

"I liked the time limit. Especially for this group, the time limit and working silently sometimes is important, because otherwise discussions easily get too long." 4:38-5:56 (C3_P3)

Especially from company 2, which was critical regarding the points and also the leader board, it was interesting to see that they valued the time limit and truly saw it as a tool able to improve their performance.

"What I really liked, the points didn't interest me at all, was the time limit! That you have to be done after a certain time and you can't just say, I'll need another hour and another and still nothing is finished. That's why I like the time limits." 8:13-8:32 (C2_P3)

Company 1 was not as convinced by using the time limits themselves ("I didn't care about the time limit." (C1_P3)). However, they did recognize them as a tool that could be used to increase their clients' efficiency:

"Yeah maybe it's a good idea for our clients. Instead of you yelling, having a timer." 3:16-3:24 (C1_P2)

Even though 11 of the participants enjoyed receiving points, only 9 participants also enjoyed the leaderboard. With 2 participants liking the leaderboard, this leaves 5 participants at feeling neutral about it. Some participants simply did not recognize the leaderboard as something more than a gimmick and did not care if they were mentioned on it.

“Assigning points and the leaderboard weren't really important for me.” 5:50-7:05 (C2_P2)

It was interesting to observe, that even though most participants made jokes about who was on the leader board and how it did not mean anything, they were still keeping a very close watch of the development throughout the levels.

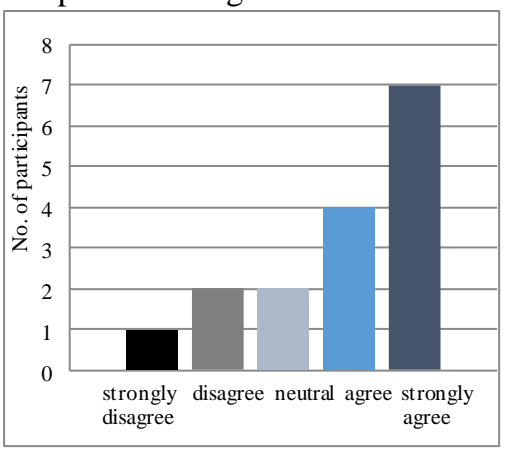

Figure 5. Question 2: Receiving points for my participation motivated me.

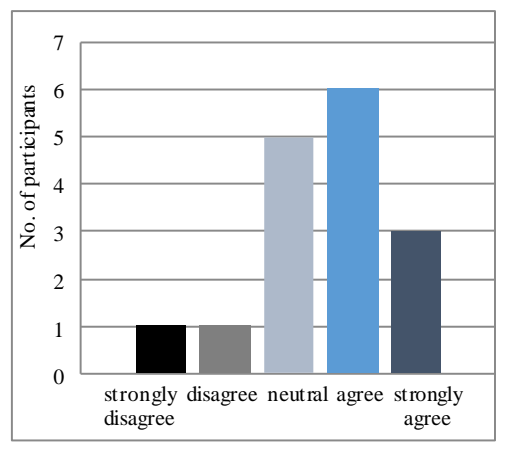

Figure 6. Question 3: The

leaderboard was motivating. 


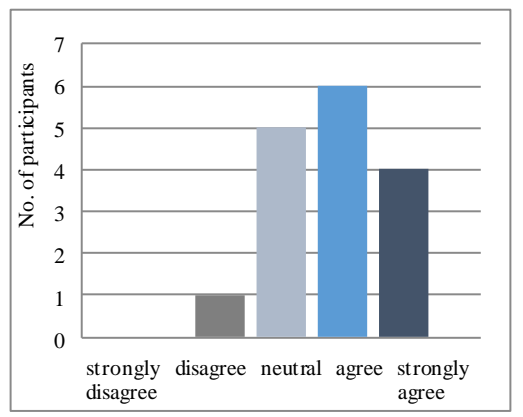

Figure 7. Question 4: The time limit was motivating.

Therefore, it can be said that the game elements helped in developing a more engaging and motivating risk management workshop as they encouraged participation and facilitated the creation of an interactive setting.

H2: Receiving feedback both from the game mechanics and from colleagues as well as the opportunity to give feedback motivates participants in gamified risk management workshops, because it increases a feeling of relatedness and autonomy.

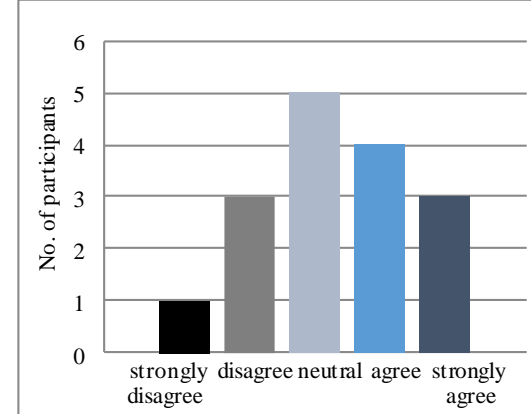

Figure 8. Question 5: Getting graded by other participants motivated me.

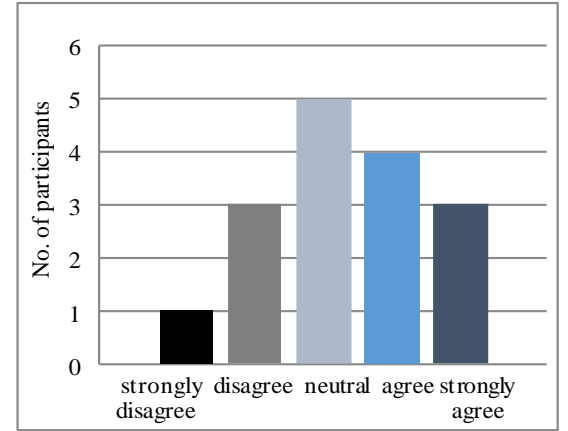

Figure 9. Question 6: Being able to grade other participants motivated me.

Feedback mechanics are generally understood as some of the most important mechanics in order to create engagement and motivation. In the workshop the participants were able to rate the ideas generated by the other participants by awarding stars to good ideas. However, the results of the survey suggest that the participants of all three workshops were rather uninterested in this mechanic. Even though participants originally contributed their ideas in an anonymous way, it was eventually difficult to maintain anonymity, simply due to the small groups of participants and also due to them feeling the need to explain their ideas. Therefore, if anonymity is not guaranteed, people become hesitant in openly evaluating others.

In this workshop, the participants seemed to prefer feedback from the game system itself, instead of receiving or giving feedback from or to peers. People tend to trust neutral feedback more, than feedback from their peers. Additionally, many people feel uncomfortable with giving feedback, be it positive or negative, to peers, especially not in a group. Feedback coming from the rules of the workshop however is less personalized and therefore does not threaten the often volatile social balance as much. However, other studies conclude that new technologies can add value and create new potential regarding both the maximization of the impact and the evaluation of a gamified activity or a serious game [57].

H3: Game elements can help to build a risk management process that minimizes the influence of cognitive biases and to improve decision making in general.

All of the participants agreed that the discussions with their team as well as with the competing team helped them making better decisions. They realized that by discussing their risk assessments they improved their evaluations - either through better understanding the risk itself by listening to more comments or simply by gaining a unanimous understanding of the risk at hand. 
pag. 76

"The discussion helped. I would have positioned the risks on the risk map differently but now after the discussion I do think that we placed them correctly. "4:25-4:40 (C1_P6)

"Otherwise we would have had a large divergence in the understanding of the risks, especially the one concerning large customers. If we hadn't developed a definition together.” 6:44-6:55 (C3_P1)

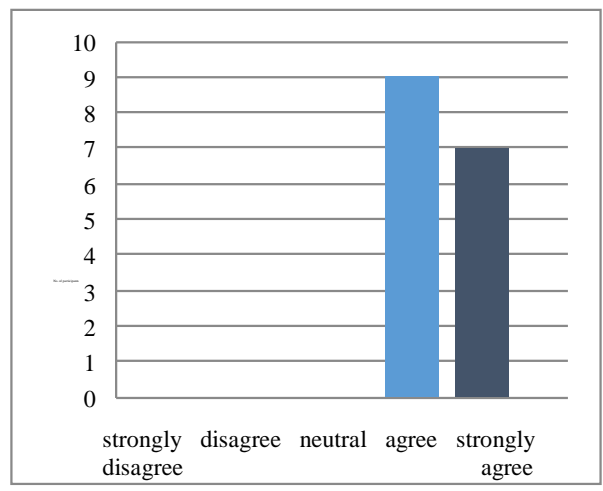

Figure 10. Question 9: The discussions in and between the groups improved general decision making.

These discussions were designed, to encourage the participants to exchange their knowledge in order to overcome the availability bias. Through the two groups gaining points for convincing the other group of their idea, the issue of groupthink and the conformity bias were addressed. In company 1 , however, the issue of hierarchy arose, since the CEO was a very dominant participant throughout the workshop. Additionally, in the group discussions the anonymity of the participants was lost. This led one of the participants of the group to say that even though she thought the discussions were helpful, that the opinions of the employees might not have been treated as equally important as those of the CEO: "Even though we don't stand a chance against our boss." 4:124:17 (C1_P3). In general, the specific use of game mechanics to address common cognitive biases was very effective. However, since there are multiple reasons for many different cognitive biases to arise, the issue of cognitive biases can arguably only be minimized rather than completely overcome.

\section{H4: The use of gamification can help creating a clear and structured risk management process that is easy to follow, to visualize and to replicate.}

One of the core ideas of the workshop was to provide the participating companies with a suggestion for a clearly structured and visualized, replicable and engaging approach to risk management.

"I agree, it was well structured. I think we all know that it is important to structure and that was made very clear here for me.” 3:37-4:29. (C3_P3)

"I think we do take the time to talk to colleagues about this in general but not like this, so structured." 5:22 - 5: 42 (C2_P1)

"I saw it as a chance to exchange ideas in a structured way." 5:50-6:05 (C2_P2)

"The visualization was very good." 10:55-10:58 (C1_P1)

This distinctly positive feedback regarding the structure of the workshop suggests that using game elements, such as the level structure, can help to structure a seemingly complicated process into a more manageable, comprehensible one. Especially helpful for creating a good structure was breaking the workshop down into different levels. Taking a look at the leaderboard in between levels gave the participants a quick break and allowed them to prepare for the next step. Additionally, having the researcher function as a moderator supported the participants in following the desired layout of the workshop. 
H5: A gamified risk management workshop has the possibility to convey knowledge and teach the practical application of theory in a safe environment.

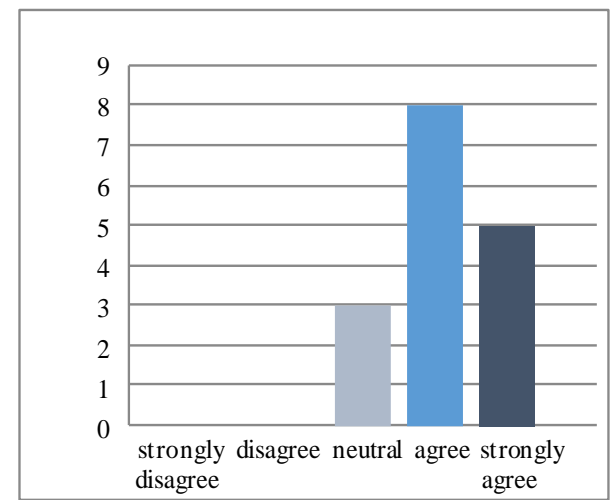

Figure 11 Question 12: The workshop increased my knowledge of risk

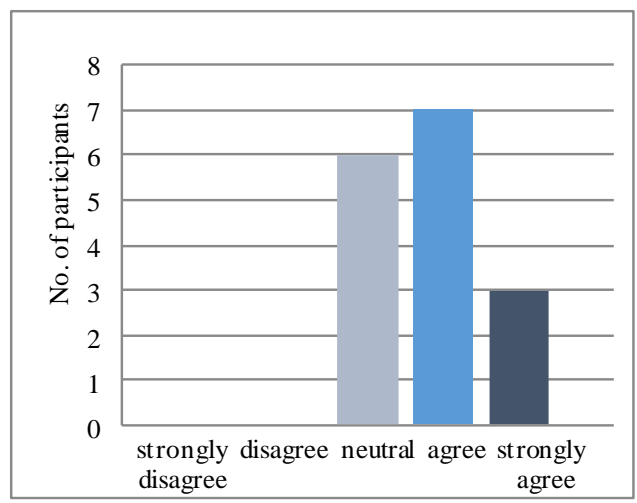

Figure 12. Question 13: The workshop showed me practical applications of risk

During the workshop, traditional risk management tools like a risk map were used without explicit explanation. The participants directly applied the tools to their company - following a learning-bydoing approach. The results of the survey support the hypothesis that being able to apply these tools in a real-life but error-tolerant setting can increase employee learning. When asked if he considered the workshop a useful tool to teach employees in SMEs about risk management, one of the participants agreed

"I think so, yes. I don't know the Berlin market, but for SMEs in Schleswig-Holstein, it should be useful.” 16:55-17:03 (C3_P1)

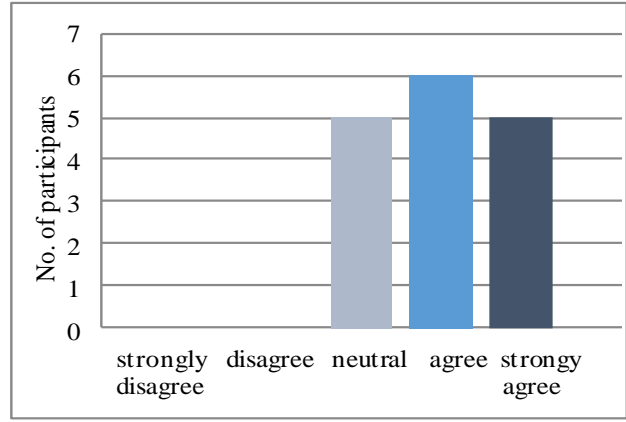

Figure 13. Question 14: I now think that risk management is more important.

Additionally, 11 of the participants agreed or strongly agreed that they perceived risk management as more important after the workshop. This is an important indicator for increasing a company's engagement in and knowledge of risk management.

Different companies and different personality types reacted differently to the game elements. The workshop design provided different game mechanics in order to (at least partially) cater the needs of all player types. A clear difference between what the companies preferred became evident. This supports the idea of choosing game mechanics suitable for the personality types at hand [38].

Singling out specific game elements from a gamified process in order to analyze their respective effectiveness is challenging, as they are often embedded in an interdependent setting and cannot be perceived separately [58]. Yet, the issue of studying the effectiveness of individual game design elements and their behavioral outcomes is highly relevant to gamification research, as it provides a more nuanced understanding of their function and usefulness in a given context [59].

\subsection{Summary of Hypotheses Testing}

Based on the data collected by observing the workshop, the survey and the focus groups, the following assumptions about the developed hypothesis can be made. 
Table 3. Results of hypothesis testing.

\begin{tabular}{l|l}
\hline Hypothesis & Result \\
H1: Game elements such as points, leaderboards, and time limits are motivating & Supported \\
in risk management at SMEs as they drive competition and provide the & \\
participants with a feeling of mastery. & \\
H2: Receiving feedback both from the game mechanics and from colleagues as & Partly \\
well as the opportunity to give feedback motivates participants in gamified risk & Supported \\
management workshops, because it increases a feeling of relatedness and & \\
autonomy. & \\
H3: Game elements can help to build a risk management process that minimizes \\
the influence of cognitive biases and to improve decision making in general & Supported \\
\hline H4: The use of gamification can help creating a clear and structured risk & Supported \\
management process that is easy to follow, to visualize and to replicate. & \\
\hline H5: A gamified risk management workshop has the possibility to convey & Supported \\
knowledge and teach the practical application of theory in a safe environment. & \\
\hline
\end{tabular}

That the game elements listed in $\mathrm{H} 1$ generally received positive feedback is obvious from both the survey and the focus groups. For example, only 2 participants did not like the points. An interesting result is that of $\mathrm{H} 2$, because the data collected in this study showed that the participants were not very motivated by receiving feedback or by giving feedback to their peers. Therefore, this might be a mechanism for only highly competitive groups, but in companies with socially oriented employees, assessing peers might not be adequate. All data collection methods showed positive results for H3. After the workshop, the participants all emphasized the positive influence of the group discussions on their decisions. Using competition to motivate groups to discuss their results seems to be a powerful tool to address and overcome issues like groupthink and the conformity bias. Being randomly assigned to groups and being an anonymous participant while playing alone helped the participants to overcome hierarchies and the authority bias. Many participants stated that they enjoyed the visualization and the structure of the workshop. It provided them with clear rules and a logically structured action approach. This might be a key success factor for risk management in SMEs. The results for H5 were surprisingly positive, with all participants recognizing that the workshop taught them about risk management in general, to practically apply theoretical knowledge, or simply about the importance of risk management.

\subsection{Limitations}

Although the data suggests strong support for the proposed hypotheses, this study cannot claim being fully representative. It is a systematic exploratory study inviting further research. Even though three focus groups are recommended in order to attain information saturation, the sample size of this study with 16 participants in total is very small, especially regarding the quantitative analysis of the conducted survey [52]. Additionally, as action research mainly depends on the researcher's observation, results might be biased. Since the companies selected had a connection to the researchers, the issue of potential participant bias also emerged.

Since the study was conducted as quasi-experimental action research, no additional test with a control group was performed. The use of a control group might be useful to determine if the game mechanics applied in this workshop were the true reason for the improved results regarding engagement and knowledge generation.

Even though the workshop was tested with three different companies, suggesting a "real-world" setting, the participants might still have been biased because they were in a workshop and observed by the researchers. Their behaviour might have differed if they had not been observed [49]. Also, the study did not take into account the influence of participant age or gender in order to obtain a reasonable sample size. These might be factors influencing the participants' perception of the workshop as well as their evaluation of it.

\section{Conclusion and outlook}

This study was aimed at bridging the identified knowledge gap of the effectiveness of applying gamification to risk management. The results of this study indicate that gamification is an 
appropriate tool for enhancing the risk management process in SMEs. All participants were convinced that the workshop presented them with new ideas and knowledge at least to a certain extent in each addressed field: motivation, knowledge and cognitive biases. Additionally, the importance of a clear and understandable structure for this gamified experience became obvious both from watching the participants and from their responses in the focus group. Concluding, it can be said that gamification can improve the risk management process in SMEs, by enhancing motivation and knowledge of the people involved while reducing their susceptibility to cognitive biases. To achieve this, the game elements have to be included in a way that a) motivates multiple player types and b) is meaningful and logical in regards to structure and function.

Risk management is an important topic for all companies, for SMEs in particular. This study suggests that it can be enhanced with the proper use of gamification. To be able to make more representative assumptions, further research could approach the idea of larger sample sizes. It might be interesting to elaborate on how different player types effect the evaluation of gamification in risk management. Also, studying long term effects of introducing gamification to the risk management process of SMEs could be valuable. The authors are interested in pursuing further research in this field, especially on the topic of IT supported interaction formats and also hope to spark the interest of fellow researchers.

\section{Acknowledgements}

This research was partly funded by the German Bundesministerium für Forschung und Bildung ("LudoLeist" project within the FHprofUnt framework).

\section{References}

[1] Falkner, E. M., Hiebl, M. R. W., Risk management in SMEs: a systematic review of available evidence, Journal of Risk Finance (Emerald Group Publishing Limited), Vol. 16, Nr. 2, pp. 122-144, 2015 http://dx.doi.org/10.1108/JRF-06-2014-0079

[2] Prentice, R. A., Valine, Y. A., Don't kid yourself, you're biased, RMA Journal, Vol. 95, Nr.10, pp. 12-17, 2013

[3] Abotsi, A. K., Dake, G. Y., Agyepong, A. R., Factors Influencing Risk Management Decision of Small and Medium Scale Enterprises in Ghana, Contemporary Economics, Vol. 8, Nr. 4, pp. 397-413, 2014

[4] Schönbohm, A., Urban, K., "Can Gamification close the engagement gap of Generation Y?", Berlin, Logos Verlag, 2014

[5] Enterprise Gamification Consultancy: Risk Management Awareness, [Online], Available at http://www.enterprisegamification.com/mediawiki/index.php?title=Risk_Management_Awareness, 2014

[6] Bajdor, P., Dragolea, L., The gamification as a tool to improve risk management in the enterprise, Annales Universitatis Apulensis Series Oeconomica, Vol. 2, Nr. 13, pp. 574-583, 2011

[7] AIRMIC, Alarm, IRM, A structured approach to Enterprise Risk Management (ERM) and the requirements of ISO 31000, [Online], Available at https://www.theirm.org/media/886062/ISO3100_doc.pdf, 2010

[8] Marcelino-Sádaba, S., Pérez-Ezcurdia, A., Echeverría Lazcano., A. M., Villanueva, P., Project risk management methodology for small firms, International Journal of Project Management, Vol. 32, Nr. 2, pp. 327-340, 2014 http://dx.doi.org/10.1016/j.ijproman.2013.05.009

[9] Clark, A., Smaller sized risk management, Canadian Underwriter, Vol. 78, Nr. 9, pp.38-42, 2011

[10] Lindegaard, S., Innovation: The 7 Key Differences Between Big and Small Companies, [Online], Available at: http://www.15inno.com/2011/10/28/free-book-making-openinnovation-work/, 2011

[11] Negus, J., 10 common ERM Challenges, Risk Management Magazine, [Online], Available from: http://www.rmmagazine.com/2010/03/01/10-common-erm-challenges/, 2010

[12] Gao, S. S., Sung, M. C., Zhang, J., Risk management capability building in SMEs: A social capital perspective, International Small Business Journal, Vol. 31, Nr. 6, pp. 677-700, 2013. http://dx.doi.org/10.1177/0266242611431094 
[13] Moore, J., Culver, J., Masterman, B., Risk Management for Middle Market Companies, Journal of Applied Corporate Finance, Vol. 12, Nr. 4, pp. 112-119, 2000. http://dx.doi.org/10.1111/j.1745-6622.2000.tb00024.x

[14] Ellegaard, C., Supply risk management in a small company perspective, Supply Chain Management: An International Journal, Vol. 13, Nr. 6, pp. 25-434, 2008

[15] Bruns, V., Fletcher, M., Banks' risk assessment of Swedish SMEs, Venture Capital, Vol. 10 No. 2, pp. 171-194, 2008 http://dx.doi.org/10.1080/13691060801946089

[16] Sukumar, A., Edgar, D., Grant, K., An investigation of e-business risks in UK SMEs, World Review of Entrepreneurship, Management and Sustainable Development, Vol. 7, Nr. 4, pp. 380-401, 2011. http://dx.doi.org/10.1504/WREMSD.2011.042892

[17] Thomas, M., Decision-making: is risk management the Prozac of modern business?, Keeping Good Companies, Vol. 64, Nr. 11, pp. 663-665, 2012

[18] Barnes, J. H. Jr., Cognitive Biases and their Impact on Strategic Management, Strategic $\begin{array}{lllllll}\text { Management Journal, Vol. 5, Nr. } & 2, & \text { pp. } & 129-137, & 1984\end{array}$ http://dx.doi.org/10.1002/smj.4250050204

[19] Harada, Y., Hunter, M., „Walking under a Ladder“: Superstition and Ritual as a cognitive bias in management decision making, Economics, Management, and Financial Markets, Vol. 7, Nr. 4, pp34-41, 2012

[20] Gigerenzer, G., Hertwig, R., Pachur, T., "Heuristics: The foundations of adaptive behaviour", 1st edition. New York: Oxford University Press, 2011 http://dx.doi.org/10.1093/acprof:oso/9780199744282.001.0001

[21] Sims, R. R., Sauser, W. I., Toward a Better Understanding of the Relationships among Received Wisdom, Groupthink, and Organizational Ethical Culture, Journal of Management Policy \& Practice, Vol. 14, Nr. 4, pp.75-90, 2013

[22] Kahr, A., Blame 'Systemic Risk' on Groupthink, American Banker, Vol. 175, Nr. 156, 2010

[23] Raval, U., Ojha, A. K., Risk perceptions of TMTs: Impact on strategic change and conformity, Academy of Management Annual Meeting Proceedings, pp. 1496-1501, 2014

[24] Lahno, A., Serra-Garcia, M., Peer effects in risk taking: Envy or conformity?, Journal of Risk \& Uncertainty, Vol. 50, Nr. 1, pp. 73-95, 2015 http://dx.doi.org/10.1007/s11166-0159209-4

[25] Agans, R. P., Shaffer, L. S. The Hindsight Bias: The Role of the Availability Heuristic and Perceived Risk, Basic \& Applied Social Psychology, Vol. 15, Nr. 4, pp. 439-449, 1994 http://dx.doi.org/10.1207/s15324834basp1504_3

[26] Marshall, A., Ojiako, U., Managing risk through the veil of ignorance, Journal $\begin{array}{llllll}\text { of Risk Research, } \quad \text { Vol. } \quad 16, \quad \text { Nr. } \quad 10, & \text { pp. } & 1225-1239, & 2013\end{array}$ http://dx.doi.org/10.1080/13669877.2013.788056

[27] Cen, L., Hilary, G., Wei, K. C. J., The Role of Anchoring Bias in the Equity Market: Evidence from Analysts' Earnings Forecasts and Stock Returns, Journal of Financial \& Quantitative Analysis, Vol. 48, Nr. 1, pp. 47-76, 2013 http://dx.doi.org/10.1017/S0022109012000609

[28] Hess, D., Orbe, S., Irrationality or Efficiency of Macroeconomic Survey Forecasts? Implications from the Anchoring Bias Test, Review of Finance, 2013, Vol. 17, Nr. 6., pp. 2097-2131, 2013

[29] Deterding, S., Dixon, D., Khaled, R., Nacke, L., Gamification: toward a definition, [Online], Available from: http://gamification-research.org/wp-content/uploads/2011/04/02-DeterdingKhaled-Nacke-Dixon.pdf, 2011

[30] Scheiner, C., Witt, M., The Backbone of Gamification - a Theoretical Consideration of Play and Game $\quad$ Mechanics, Anline], Available at: http://subs.emis.de/LNI/Proceedings/Proceedings220/2372.pdf , 2011

[31] Gartner, Gartner says by 2014, 80 Percent of Current Gamified Applications Will Fail to Meet Business Objectives Primarily Due to Poor Design, [Online], Available at http://www.gartner.com/newsroom/id/2251015, 2012

[32] Kooij, K., Hoogendoorn, E., Spijkerman, R., Visch, V., Validation of Games for Behavioural Change: Connecting the Playful and the Serious, International Journal of Serious Games, Vol. 2, Nr. 3, 2015

[33] De Gloria, A., Bellotti, F., Berta, R., Lavagnino, E., Serious Games for education and training, International Journal of Serious Games, Vol. 1, Nr. 1, 2014 http://dx.doi.org/10.17083/ijsg.v1i1.11 
[34] Ryan, R., Deci, E., Intrinsic and extrinsic Motivation: Classic Definitions and new directions, Contemporary Educational Psychology, Vol. 25, pp. 54-67, 2000 http://dx.doi.org/10.1006/ceps.1999.1020

[35] Deterding, S., The Lens of Intrinsic Skill Atoms: A Method for Gameful Design, HumanComputer Interaction, Vol. 30, Nr. 3-4, pp. 294-335, 2015 http://dx.doi.org/10.1080/07370024.2014.993471

[36] Cunningham, C., Zichermann, G., "Gamification by Design: Implementing game mechanics in web and mobile apps”, 1st edition, Sebastopol: O'Reilly, 2011

[37] Library Technology Report, Designing Gamification in the right way; Vol. 51, Nr. 2, pp. 2935,2015

[38] Bartle, R., Hearts, clubs, diamonds, spades: Players who suit MUDs, Journal of MUD Research, Vol. 1, Nr. 1, [Online], Available at: http://www.mud.co.uk/richard/hcds.htm, 1996

[39] Lichtenvoort, D., "Video game element incentives in cross functional enterprise", Hamburg: Diplomica Verlag GmbH, 2014

[40] Pandey, A., Gamification Of Compliance Training: A Case Study, [Online], Available at http://elearningindustry.com/gamification-of-compliance-training-serious-game-concept, 2014

[41] Afify, M. F., Action Research: Solving Real World Problems, Tourism \& Hospitality Research, Vol. 8, Nr. 2, pp. 153-159, 2008 http://dx.doi.org/10.1057/thr.2008.13

[42] Burnes, B., Kurt Lewin and the Planned Approach to Change: A re-appraisal, Journal of Management Studies, Vol. 41, Nr. 6, pp. 977-1002, 2004 http://dx.doi.org/10.1111/j.14676486.2004.00463.x

[43] Hammersley, M., Action Research: A contradiction in terms?, Oxford Review of Education, Vol. 30, Nr. 2, pp. 165-181, 2004 http://dx.doi.org/10.1080/0305498042000215502

[44] Hron, A., Kompe, H., Otto, K.-P., Wächter, H., "Aktionsforschung in der Ökonomie“, Frankfurt (Main) / New York: Campus Verlag, 1979

[45] Duschek, S., Sydow, J., “Aktionsforschung - Königsweg zu Netzwerkzeugen?“ In: Sydow, J.; Duschek, S. (HRsg), Netzwerkzeuge: Tools für das Netzwerkmanagement. Springer Fachmedien Wiesbaden, 2013 http://dx.doi.org/10.1007/978-3-658-00258-9_11

[46] Nogueira, J. M., Romero, D., Espadas, J., Molina, A., Leveraging the Zachman framework implementation using action research methodology - a case study: aligning enterprise architecture and the business goals, Enterprise Information Systems, Vol. 7, Nr. 1, pp. 100132, 2013 http://dx.doi.org/10.1080/17517575.2012.678387

[47] Devlin, A. B., Murphy, T. P., An architecture for a business and information system, IBM Systems Journal, Vol. 27, Nr. 1, pp. 60-80, 1988 http://dx.doi.org/10.1147/sj.271.0060

[48] Avison, D., Lau, F., Myers, M., Nielsen, P., Action Research, Association for Computing Machinery, Action Research Communications of the ACM, Vol. 42, Nr. 1, pp. 94-97, 1999 http://dx.doi.org/10.1145/291469.291479

[49] Bradley, K., Quasiexperimental Research, [Online], Available at: http://www.education.com/reference/article/quasiexperimental-research/, 2009

[50] McTaggart, R., "Guiding Principles for Participatory Action Research", in McTaggart, R. Ed. (1997) Participatory Action Research, International Contexts and Consequences, State University of New York Press, Albany, 1997

[51] Coughlan, P., Coghlan, D., Action Research for Operations Management, International Journal of Operations \& Production Management, Vol. 22, Nr. 2, pp. 220-240, 2002 http://dx.doi.org/10.1108/01443570210417515

[52] Lewis, P., Saunders, M., Thornhill, A., "Research methods for business students", 5th edition. Edinburgh Gate: Pearson Education Limited, 2009

[53] Carson, D., Gilmore, A., Perry, C., Grønhaug, K., “Qualitative Marketing Research", London: Sage, 2001 http://dx.doi.org/10.4135/9781849209625

[54] Krueger, R. A.; Casey, M. A., "Focus Groups: A Practical Guide for Applied Research" (3rd edn), Thousand Oaks, CA: Sage, 2000 http://dx.doi.org/10.1037/10518-189

[55] Dresing, T., Pehl, T., Schmieder, C., Manual (on) Transcription, Transcription Conventions, Software Guides and Practical Hints for Qualitative Researchers, 3rd English Edition, Marburg, [Online], Available at: http://www.audiotranskription.de/english/transcriptionpracticalguide.htm, 2015

[56] Kvale, S., "Interviews". Thousand Oaks, CA: Sage, 1996

[57] Catalano, C. E., Luccini, A. M., Mortara, M., Best practices for an effective Design and Evaluation of Serious Games, International Journal of Serious Games, Vol. 1, Nr. 1, 2014 
pag. 82

[58] Landers, R. N., Bauer, K.N., Kallan, R. C., Gamification of task performance with leaderboards: A goal setting experiment, Computers in Human Behavior, http://dx.doi.org/10.1016/j.chb.2015.08.008, 2015

[59] Mekler, E. D., Brühlmann, F., Tuch, A. N., Opwies, K., Towards understanding the effects of individual gamification elements on intrinsic motivation and performance, Computers in Human Behavior, http://dx.doi.org/10.1016/j.chb.2015.08.048, 2015 